\title{
Science in American Society: A Generation of Historical Debate
}

\section{Citation}

Rosenberg, Charles E. 1983. Science in American society: A generation of historical debate. Isis $74(3):$ 356-367.

\section{Published Version}

doi:10.1086/353304

\section{Permanent link}

http://nrs.harvard.edu/urn-3:HUL.InstRepos:4730385

\section{Terms of Use}

This article was downloaded from Harvard University's DASH repository, and is made available under the terms and conditions applicable to Other Posted Material, as set forth at http:// nrs.harvard.edu/urn-3:HUL.InstRepos:dash.current.terms-of-use\#LAA

\section{Share Your Story}

The Harvard community has made this article openly available.

Please share how this access benefits you. Submit a story.

Accessibility 


\title{
CRITIQUES \& CONTENTIONS
}

\section{Science in American Society}

\section{A Generation of Historical Debate}

\author{
By Charles Rosenberg*
}

$\mathrm{T}$

WENTY YEARS AGO, the place of science in American society did not really constitute a problem for historians; within the larger discipline of history it attracted only a handful of devotees-most of them practitioners of a still unfashionable social or institutional history. Within the rather different confines of a still newly fledged history of science, scholars concerned with the development of science in America occupied a marginal place-their very concern with matters national and social dictating a comparatively low status. If the ultimate structures of science were intellectual, the confining of scholarship within national boundaries seemed arbitrary, perhaps justified occasionally by a desire to clarify the circumstances of particularly significant innovations but otherwise inconsistent with the necessarily international structure of knowledge itself. General historians who concerned themselves with science in America felt similarly isolated from the mainstream of their particular discipline, where the big questions were still political: causation of the American Revolution and Civil War, the nature of Progressivism and Jacksonian Democracy, the failure of Reconstruction.

The would-be student of science in America could only feel defensive as hethere were not many shes-contemplated the existing canon of significance. The sociologists and political scientists who interested themselves in the field seemed weak allies in confronting a literature dominated by centuries before the nineteenth and problems largely intellectual. Moreover, the Americanists' stock of empirical knowledge was thin and skewed toward the eighteenth and early nineteenth centuries, a period, ironically, when the place of North America in the world of learning was as marginal intellectually in relation to the metropolis as it was geographically. Equally limiting was a discursive and unquestioning style; the study of American science was characterized by much description and precious little analysis. It was still possible to announce with the enthusiasm of novelty that connections did indeed exist between society and the internal world of science, as though that constituted in itself a meaningful statement. The only well-established tradition of formal social analysis that had even fitfully

\footnotetext{
* Department of History, University of Pennsylvania, Philadelphia, Pennsylvania 19104.

Delivered as the History of Science Society Lecture, 30 October 1983 (a few minor textual changes have been made).
} 
dressed such matters-the Marxist-hardly existed as an option in 1962; it was banished from the American academic scene by politics and, perhaps more importantly, by a pervasive atheoretical and empirical style of historical discourse. To most general historians, the past role of science and technology was selfevident; almost all, including the neo-Marxist, were whigs and modernizers without being aware of it. Like the gentleman who discovered to his surprise that he had been speaking prose for years, it was the common sense of the matter. Historians simply assumed that science had played a direct, central, and unquestioned role in promoting social change in the West. And this cultural evolution was as implicitly beneficent as it was inevitable; a positive moral tone surrounded the accomplishments of man's mind. The past two decades have made it difficult to sustain this point of view; change may still be unavoidable, but its shape is unpredictable and it no longer seems necessarily benevolent.

Inevitable as these skeptical trends may appear in retrospect, they were hardly apparent a generation ago. When, as a beginner, I first tried to take stock of the field in 1963, I expected other developments to reshape the historical study of science in America. ${ }^{1}$ It seemed clear that the history of science discipline was divided in practice between an internalist majority and an externalist minority; while no one defended the logic of this alignment, it nevertheless described an undeniable reality. The "big problem" seemed, as I saw it, to reside in the difficulty of finding an approach that would soften the rigidity of this intractable, yet logically indefensible situation.

In the past generation this picture has shifted dramatically. Although a minority of enthusiasts feel that they have discovered an appropriate method for investigating such questions, we can hardly be said to have solved the problem of relating internal and external approaches; yet to many of those who have contributed to the field in the past two decades it must seem like an irrelevant and even provincial matter-a spat between two equally obscurantist wings of a desiccated scholarship. The controversy between internalist and externalist has been overtaken by history itself. New motivations have attracted a new breed of practitioner; and to a good many such, the role of science-and especially its applied aspects-is not simply a subject for academic inquiry, but a scandalously neglected field for moral and political revelation. A host of such critics have begun to study the place of science, medicine, and technology in American society, and only a minority feel a primary loyalty to the history of science as a discipline. Many do not even think of themselves as historians. This is a generation bounded by Silent Spring and Three Mile Island; it is a generation during which Michel Foucault has replaced Robert Merton as our most widely influential sociologist of knowledge ${ }^{2}$ it is a generation that lived through a war

\footnotetext{
${ }^{1}$ Charles Rosenberg, "On the Study of American Biology and Medicine: Some Justifications," Bulletin of the History of Medicine, 1964, 38:364-376 (delivered at the annual meeting of the History of Science Society, December 1963).

${ }^{2}$ Recent years have seen an efflorescence of Foucault exegesis; for guidance in this literature, see Hubert L. Dreyfus and Paul Rabinow, Michel Foucault: Beyond Structuralism and Hermeneutics (Chicago: Univ. Chicago Press, 1982); and Charles C. Lemert and Garth Gillan, Michel Foucault: Social Theory as Transgression (New York: Columbia Univ. Press, 1982). What seems particularly clear in evaluating reactions to Foucault is that his extraordinary political and intellectual influence is based to a good extent on his delegitimation of the knowledge and authority of the purveyors and invokers of the human sciences. The contrast with the form and assumptions of Mertonian sociology is apparent.
} 
in Indo-China, a war that juxtaposed high technology and a related bureaucracy with a beautiful natural setting and the traditional ways of a peasant societyand thus recalled a much older and morally resonant contrast between the works of God and those of man. Perhaps most important, these have been decades during which the seemingly inevitable connection between knowledge and authority has become not a necessary-and thus moral-response to complexity in social structure, but an arbitrary imposition of interested control. What had been a marginal aspect of the history of science has become a bustling field in history generally, as well as an increasingly prominent element in the eclectic mosaic of interests and motivations that make up the history of science in 1982 .

The development of a critical, and even antagonistic, attitude toward the past and present role of science in the United States is related to the growth of a more critical, and self-consciously political, spirit among American historians generally and, more specifically, to a growth of interest in the role of knowledge in American society. To many such recent historians of organized knowledge, the intellectual tools of past scholars and administrators have become props for the maintenance of class, role, and gender status-and not ever-more refined approximations of a biological or social reality. To these critics, the variously internalist canons of the history of science, technology, and medicine were merely epiphenomena, reflecting the pretensions of a learned community that chose to hold itself above the social context and consequences of its acts. Not surprisingly, this revisionist spirit has already begun to provoke a backlash of hostile counterrevisionism; we have recently heard anxious lamentations over the emergence of a history of science without science, of a history of medicine without doctors. ${ }^{3}$ Yet this emotionally laden debate so characteristic of today's intellectual climate has in fact obscured a rather more complex past by polarizing and monolithically conflating critical, left, and externalist positions on the one hand and internalist and socially conservative positions on the other.

During the past two decades, scholars concerned with the historical relationship between science and society in the United States have been influenced by a number of approaches. Some have been relatively ephemeral in their influence, others more lasting. With the understanding that these are not entirely exclusive categories, let me suggest three trends which have appealed more or less strongly to historians of American science during the past generation. One, which seemed especially promising in the middle and late $1960 \mathrm{~s}$, reflected contemporary sociology of science, especially its emphasis on norms and institutional structures: historians seeking to emulate such sociological work also began to urge-and on occasion to practice-the study of the scientific community in quantitative terms, wherever possible. A second trend, chronologically subsequent but ultimately of wider impact among general readers, was, as I have already implied, a critical emphasis on the ideological uses of science; closely connected to this development was an increasing interest in the history of the social sciences and especially of their social uses. Related to this concern

${ }^{3}$ [Leonard Wilson], "Medical History with Medicine," Journal of the History of Medicine, 1980, 35:5-7; Charles C. Gillispie in remarks to the A.A.A.S. as reported by William J. Broad, "History of Science Losing Its Science," Science, 1980, 207:389; [Leonard Wilson], "Schizophrenia in Learned Societies: Professionalism vs. Scholarship," J. Hist. Med., 1981, 36:5-8; Lloyd Stevenson, “A Second Opinion," Bull. Hist. Med., 54:134-140; Nathan Reingold, "Science, Scientists, and Historians of Science," History of Science, 1981, 19:274-283. 
with the use of scientific and medical authority as cultural ideology was a desire to evaluate the social impact of technology, medicine, and the applied sciences. In retrospect it seems apparent that the motivation for such scholarship grew not so much out of concern for the community of scientific practitioners and their ideas as out of a critical attitude toward the social role of that community and the social effects of its knowledge. A third trend in the past generation's study of American science has been an ever-increasing interest in the twentieth century and especially in the role of big science, the foundations, industry, and government in the scientific enterprise:

In the mid-1960s it might well have appeared that the concepts and tools of contemporary sociology were on the point of reshaping our understanding of the scientific community and its historical development. It was, for example, a period during which something called professionalization seemed a particularly helpful organizational framework. ${ }^{4}$ It was a period too when quantitative methods first promised to make studies of publication, citation behavior, and recruitment sensitive tools for anatomizing the shape and evolutionary pattern of the scientific community. Contemporary sociology provided powerful and prestigious models; yet their overall impact has been relatively slight. Though historians of science have often cited sociological studies and generalization, and on occasion have published work derived from such models, they actually employed these tools and concepts with comparative caution. There is no substantial body of monographic work on the history of American science strongly shaped by the sociology of the 1960s. This lack is particularly striking because it was a period when historians generally were much taken with the prestige and quantitative techniques of the social sciences. It was, for example, a high point in the influence of behavioral political science among students of American political history-an influence which is still very much alive in today's scholarship. It was, similarly, a period when econometrically oriented economic history triumphed decisively over a more traditional institutional approach.

There are some conspicuous exceptions to this generalization; it would be unfair to argue that this past generation's sociology has exerted no influence at all over scholarship in the history of science. The attempt to document and anatomize the professionalization of science in America, for example, was one such focus of influence. It benefited from the advantage of seeming to be something both significant in itself and useful as an indicator of the implied developmental pattern of the scientific community; and perhaps most enticingly, it promised to be quantitatively measurable through the choice of appropriate indicators. Professionalization seemed, finally, to relate the history of America's learned community to the multifaceted yet ultimately symmetrical development of society generally. Ideas about modernization, as I have already suggested, fit unobtrusively into the whiggish assumptions so prevalent in the history of science. The growth and specialization of the several scientific disciplines, like that of the

\footnotetext{
${ }^{4}$ George H. Daniels was particularly influential in advocating the usefulness of this approach; see Daniels, "The Process of Profesșionalization in American Science: The Emergent Period, 1820 1860,' Isis, 1967, 58:151-166; Daniels, American Science in the Age of Jackson (New York: Columbia Univ. Press, 1968). A dozen years ago I was far more sanguine about the impact of contemporary sociology: see Charles Rosenberg, "On Writing the History of American Science," in The State of American History, ed. Herbert J. Bass (Chicago: Quadrangle Books, 1970), pp. 183196.
} 
traditional learned professions, both reflected and helped constitute the development of a characteristically modern society. And despite a growing skepticism in the past decade in regard to the usefulness of the so-called modernization framework, the study of nineteenth- and early twentieth-century professionalization has left behind a sediment of empirical work and a continued core of interest in professionalization. It has become abundantly clear, however, that some of our earlier notions of professionalization were over-schematized and imprecise. $^{5}$

Let me suggest two other exceptions to my generalization about the comparatively slight impact of the empirical sociology of science on the writing of its history. One is the work of Joseph Ben-David, whose discipline-oriented case studies have been widely cited and assimilated by historians of science. ${ }^{6}$ Unlike most of his peers in the 1960s, Ben-David was genuinely interested in specific historical events-particularly, of course, the role of institutional innovation and structure in intellectual change. Though constituting at first glance a kind of reductionist microeconomics of academic careerism, Ben-David's work has had a lasting impact in emphasizing the interrelationship between career choice, the structure of academic options, and intellectual activity. Many historians who do not share Ben-David's earnestly positivistic faith have nevertheless been influenced by him.

Thomas Kuhn's Structure of Scientific Revolutions constitutes another sort of exception to my generalization; in emphasizing the significance of a particularand studiable-scientific community as the producer and validator of knowledge, he succeeded in underlining both the provisional quality of that knowledge and the interactive relationship between ideas and the precise historical setting of their producers. ${ }^{7}$ Thus he maintained the traditional primacy of intellectual structure and change, while maintaining the need to insert that idea-centered concern into a specific historical and disciplinary context. In doing so he not only made the social conditions of innovation more relevant to intellectually oriented historians of science, but attracted the interest of a good many social scientists and general historians. It might be argued that Kuhn can hardly be construed as a sociologist in the sense that the term would have been understood in the American academic community in the 1960s and early 1970s; indeed, his appeal rested, I think, upon his practical-if implicit-rejection of accepted sociological modes of analysis and conventional subject matters. His point of view could be assimilated to rather different scholarly traditions, those of a European-

\footnotetext{
${ }^{5}$ For some thoughtful reflections on this question, see Laurence Veysey, "The Plural Organized Worlds of the Humanities," in The Organization of Knowledge in Modern America, 1860-1920, ed. Alexandra Oleson and John Voss (Baltimore/London: Johns Hopkins Univ. Press, 1979), pp. $58-63$.

6 Joseph Ben-David, "Roles and Innovations in Medicine," American Journal of Sociology, 1960 , 65:557-568; Ben-David and Avraham Zloczower, "Universities and Academic Systems in Modern Societies,"' European Journal of Sociology, 1962, 3:45-84; Ben-David, "Scientific Productivity and Academic Organization in Nineteenth Century Medicine," American Sociological Review, 1960, 25:828-843; Ben-David and Randall Collins, "Social Factors in the Origins of a New Science: The Case of Psychology, Am. Sociol. Rev., 1966, 31:451-465; Ben-David, The Scientist's Role in Society: A Comparative Study (Englewood Cliffs, N.J.: Prentice-Hall, 1971).

${ }^{7}$ See the revised edition, Thomas S. Kuhn, The Structure of Scientific Revolutions (2nd. ed., Chicago: Univ. Press, 1970). The Kuhn "literature" is voluminous; for access see Barry Barnes, T. S. Kuhn and Social Science (New York: Columbia Univ. Press, 1982); Nathan Reingold "Through Paradigm-Land to a Normal History of Science," Social Studies of Science, 1980, 10:475-496.
} 
style sociology of knowledge and an intellectualistic and priority-oriented history of science; while his method resembled in operational terms nothing so much as the best of established history-department intellectual history. Thus the enormous vogue of Kuhn's work only emphasizes the failure of mainstream sociology to have engaged the interest of most historians of science, of whatever orientation.

The formalism of the past generation's more standard sociological fare appealed neither to those concerned with the internal texture of scientific ideas nor to those committed to understanding the ways in which science fits into society. Neither point of view found the empirical work of our sociology departments in the 1960s and early 1970s consistently relevant. And that body of middle-level theory and empirical work has proved in retrospect a blunt tool for the analysis of particular historical problems.

Let me note in passing that similar observations might be made about the relationship between science policy and the writing of the history of science; for that body of work describing itself as science policy analysis has exerted even less influence on the history of science than its American first cousin, the sociology of science. Historians have not been attracted to a study of policy bereft of politics (or history) and of science without ideas. Again neither historians of science concerned with its impact on society nor their peers fascinated by the internal development of scientific ideas have been attracted by the literature of science policy; even those historians of science who have begun to work on twentieth-century problems and the creation of "big science"' have only infrequently assimilated and reflected science policy concerns in their own work.

Though it was difficult to have predicted two decades ago, the development which has had the greatest impact on the study of science in America-on historians generally and certainly on the common reader-has been an extraordinary efflorescence of interest in the use of scientific ideas and authority as ideology and, paralleling this, a related interest in the political and economic impact of applied science and medicine. The roots of this phenomenon are varied, interrelated, and obvious: the Civil Rights movement, the women's movement, environmentalism, Vietnam. The ideological themes are familiar enough: the place of woman as biologically determined, the epistemological legitimacy of psychiatric diagnoses and the social role of psychiatry, eugenics and racism, the nature of intelligence, the role of schools, testing and industrial psychology in the ordering and rationalizing of society from kindergarten to the workplace. This critical spirit has similarly inspired enthusiastic interest in the social sciences-and especially their policy implications. The histories of anthropology, sociology, and political science, like the history of psychiatry, have found a new constituency, one concerned primarily with the hegemonic uses made of these supposedly value-free fields. Many of those contributing to this critical literature have never read Mannheim, Habermas, or Gramsci-but seem to know perfectly well that they find something insidious in what they see as the interested uses made of purportedly objective ideas.

A similarly critical spirit has inspired a vigorous body of research into the history of the applied sciences and medicine. The relationship between agribusiness and agriscience, between industry and high-technology-oriented education, the economic behavior of physicians and other health providers, have 
all attracted a growing historical attention in the past dozen years. ${ }^{8}$ The history of technology has similarly shown increasing signs of moving closer and closer to its neighbors, business, social, and labor history, and further away from its older allies, economic history and the history of the physical sciences.

I have touched briefly in describing this new history on a good many substantive themes. And this diversity of subject is paralleled by a diversity among its practitioners, many of whom do not consider themselves historians of science-or even professional historians. As I have implied, however, they are bound together by an underlying thematic unity, one that centers on the practical and ideological roles of science and technology in perpetuating-and in part constituting-a particular social order (and in some versions assuring the status of those keepers and producers of esoteric knowledge whose task it has been to defend this social order). ${ }^{9}$ Knowledge, the argument follows, is rarely value free, but legitimates and reflects the place and thus interests of those who employ it.

Interest, of course, implies structure. This newer generation of students of the social uses of science has been particularly concerned to place knowledge and its keepers in a hierarchical network of social relations. Implicit in this point of view is the assumption that the ideological uses of scientific ideas and the social uses of technology are determined by existing relationships of social and economic power. Male power expresses itself through the ideas of medical men, psychiatrists, and social scientists. White hegemony expresses itself through the formulations of a racist biology and social science. Industrial psychology was created in response to the need to rationalize the workplaces of industrial capitalism. Native-born Americans expressed both their alarm and their power by invoking the findings of biological and social science to explain the inferiority of America's new immigrants, finally legitimating an exclusionist immigration policy in the 1920s. An anxious majority employs psychiatry to stigmatize the deviant.

Recent scholarship has viewed critically the material products of science and technology as well as their ideological uses. Even where the fruits of scholarly and technical enterprise produce seemingly useful goods, they tend to be available selectively - as in agriculture, where the works of applied science have tended to make the rich richer and the poor ex-farmers. In medicine, mortality and morbidity statistics still mirror fundamental social inequities-despite a therapeutic armamentarium almost entirely reconstituted in the past century. The products of industry seem in the works of some recent students to have been calculated more for the maximization of consumption than the rational improve-

\footnotetext{
${ }^{8}$ See, e.g., David F. Noble, America by Design: Science, Technology, and the Rise of Corporate Capitalism (New York: Knopf, 1977); E. Richard Brown, Rockefeller Medicine Men: Medicine and Capitalism in America (Berkeley/Los Angeles: Univ. California Press, 1979); Jim Hightower, Hard Tomatoes, Hard Times: A Report of the Agribusiness Accountability Project . . (Cambridge, Mass.: Shenkman, 1973). Not all recent studies in this area are marked by so critical a spirit.

${ }^{9}$ For a particularly heavy-handed version of this argument, see Burton Bledstein, The Culture of Professionalism: The Middle Class and the Development of Higher Education in America (New York: Norton, 1976). More nuanced and valuable studies dealing with the relationship between knowledge and the social position of its keepers and disseminators are Mary O. Furner, Advocacy and Objectivity: A Crisis in the Professionalization of American Social Science, 1865-1905 (Lexington: Univ. Kentucky Press, 1975); and Thomas L. Haskell, The Emergence of Professional Social Science: The American Social Science Association and Nineteenth-Century Crisis of Authority (Urbana: Univ. Illinois Press, 1977).
} 
ment of man's lot. ${ }^{10}$ The past generation of scholars and social critics has, in short, firmly placed-indeed shoved-the men and ideas of science and its applied fields into a world of power and exploitation, of administrative structure and profit maximization, of historical accident and necessity.

There are few signs that this interest will flag in the near future. And though this trend has in general played a salutary role in expanding the history of science canon-certainly in making it relevant to the concerns of general historians-a few words of caution may be in order. First, indignation at the inequitable distribution and often undesirable uses of technology has in the minds of some critics produced an almost categorical rejection of the new social options and equities that scientific and technical change have made possible. Historians of the nineteenth and earlier centuries will be very much aware of the realities of famine, sickness, infant mortality, and the brutalizing effects of want and premodern exploitation-the fundamental realities of man's condition in traditional society. I must confess that I find it difficult to understand the nostalgic admiration-shared ironically by some romantics of both left and right-for the spiritually rewarding virtues of premodern village society.

The ideological uses of science too are more complex and ambiguous than some of its recent students would allow. Individual studies have again and again identified socially interested functions played by such ideas; yet $a$ function is not the function and function is not meaning. In its most widely used form, the term ideology implies structure and the unequal exercise of power. At the other end of our spectrum of casual linguistic usage is the term world view, expressing a collectively agreed-upon and thus collectively valuable way of organizing social reality. Obviously neither of these ends of the value spectrum provides a perspective entirely adequate for understanding the social uses of agreed-upon belief, especially in a diverse modern society. In the future, historians concerned with the ideological uses of science will have to incorporate both ways of looking at their subject, seeing ideas both as potentially hegemonic and as socially necessary exercises in collective belief. This is a particularly challenging task for historians of the late nineteenth and twentieth centuries; for our world viewirrespective in some ways of class and social location-incorporates scientific authority and scientific descriptions of reality as a fundamental element. If we are to understand our society's ways of conceptualizing the world, these formulations must be approached with a due regard for their diffuseness and multivocality.

For a good many self-identified historians of science, however, these problems will always remain marginal, for they relate to the social uses of science and not primarily to scientific ideas and the scientific community. The critical approach I have been describing avoids a direct confrontation with the internal logic of scientific ideas and the workings of the scientific community, which are, after all, the definitive tasks of the historian of science, technology, or medicine.

A third, and not entirely unrelated, trend of the past two decades has been a growth of scholarly interests in big science and the foundations, in the role of government, in the knowledge factories like Caltech and MIT. Twenty years ago

\footnotetext{
${ }^{10}$ See, e.g., Stewart Ewen, Captains of Consciousness: Advertising and the Social Roots of the Consumer Culture (New York: McGraw-Hill, 1976).
} 
it was easier to find historical articles on colonial botany than on the development of biochemistry or cytology; a younger scholar or graduate student today is far more likely to be familiar with the career of Robert Millikan, Warren Weaver, Thomas Hunt Morgan, or George Ellery Hale than that of David Rittenhouse or Alexander Garden. Though I would not have us ignore our eighteenth- and early-nineteenth-century roots, this shift in emphasis seems only appropriate. Both the scale and centrality of the twentieth-century scientific enterprise and the enticing availability of newly opened archival resources have made recent science attractive and highlighted the significance of support mechanisms for science and the key role of the scientific entrepreneur, whether based in a university department or in the administrative offices of a strategically located foundation. The scale and specialization of mid-twentieth-century science has allowed us to demonstrate a relationship between innovation and specific, documentable policy decisions-just the sort of finding which intrigues the historian and inspires new research. ${ }^{11}$

This interest in recent science is an important and stable trend, one which has already reshaped the standard canon of American science. But it too has exhibited some asymmetries of emphasis. First, the availability of a number of strategic manuscript collections has perpetuated our natural tendency to write a history of science focused on cutting edges and elite organizers, no matter what the original motivation of the scholar undertaking the study. ${ }^{12}$ Whether one accepts this as a natural outcome of the competitive and intellectualistic essence of science or as a reflection of the necessarily centralized nature of twentiethcentury decision-making, it nevertheless results in a partialistic canon, one weighted toward trend-setting subdisciplines and a handful of key institutions and decision makers. But these are relatively minor cavils; it is clear that in the institutional growth and social impact of science in twentieth-century America we have a set of problems that will keep historians at work for generations. And like the burgeoning interest in the ideological uses of science, this concern with contemporary science and its modes of support inevitably brings the history of science closer to the concerns of general historians; to some extent this has been the case with Kuhn's influence and the desire to explore professionalization; all have helped create an increasing rapprochement between historians of science and technology and the larger field of history.

Thus far I have been broadly sketching some paths explored during the past generation. By way of conclusion let me suggest-and perhaps predict-some directions for the next two decades.

First, we have hardly solved the problem of relating scientific ideas and the structure of the scientific community to their extrascientific context. Though this area has been the occasion for an abundance of programmatic statements, it has

\footnotetext{
${ }^{11}$ For 20th-century biochemistry, see Robert Kohler, From Medical Chemistry to Biochemistry: The Making of a Biomedical Discipline (Cambridge: Cambridge Univ. Press, 1982); and Kohler, "Warren Weaver and the Rockefeller Foundation Program in Molecular Biology: A Case Study in the Management of Science," in The Sciences in the American Context, ed. Nathan Reingold (Washington, D.C.: Smithsonian Institution Press, 1979), pp. 249-293. For 20th-century American physics see, e.g., Daniel Kevles, The Physicists (New York: Knopf, 1977); Robert Kargon, Robert Millikan (Ithaca: Cornell Univ. Press, 1982).

${ }_{12}$ The availability of the Rockefeller Archives Collection provides a particularly striking example.
} 
been a somewhat less fruitful source of empirical investigation. ${ }^{13}$ (At the same time, the problem has come to seem increasingly complex as work on the twentieth century has made clear the diversity of such interrelationships). One encouraging trend is a growing interest in the disciplinary approach; as I have suggested elsewhere, the discipline-or in the twentieth century increasingly the sub-subdiscipline or problem cluster-is the structuring unit of intellectual activity, the entity organically incorporating intellectual, institutional, and personal elements in shaping the reality perceived and experienced by individual scientists. Such thought-defined units are ordinarily understood and accepted by contemporaries, not imposed by the historian's retrospective concerns. ${ }^{14}$ Though one may differ about the mechanisms producing innovation, one can hardly approach even a problem in the history of pure mathematics or physics in 1982 without at least a gesture in the direction of placing one's protagonists in a generation and discipline-specific framework. These are realities which no past actor could well have ignored.

Which suggests another important and perhaps underappreciated approach to relating the scientists' ideas to the context in which he or she develops them. And this is implied by my use of the term "actor" and centers on tracing the scientist through his or her life course as he or she chooses among a particular configuration of social, institutional, and intellectual options. A key problem, of course, lies in selecting appropriate units of analysis. One, obviously, is individual biography; another is the collective biography of small groups, especially those defined by a commonality of intellectual commitment and institutional location.

Biography, a somewhat less than fashionable genre, deserves a word of defense and explication. ${ }^{15}$ What could be a more organic and unassailably coherent sample of historical data than a man's life? Although every life is idiosyncratic, no life is random; every life course reflects a specific configuration of social options-those chosen, as well by implication as those unavailable or unchosen. To follow the choices made by a particular actor is necessarily to transcend the sterile categories of internal and external, social or intellectual. Let me refer, by way of illustration, to a particularly well known, if not notorious, recent example-the life of J. B. Watson as presented in his Double Helix: when the self-consciously eager young man decides how he is to invest his intellectual capital in making a career, is he making an institutional or an intellectual choice?

\footnotetext{
${ }^{13}$ For a sophisticated guide to work in this area, see Steven Shapin, "History of Science and its Sociological Reconstructions," Hist. Sci., 1982, 20:157-211. See also Barry Barnes and Steven Shapin, eds., Natural Order: Historical Studies of Scientific Culture (Beverly Hills/London: Sage, 1979); Barry Barnes, Interests and the Growth of Knowledge (London: Routledge \& Kegan Paul, 1977).

${ }^{14}$ Gerard Lemaine, Roy Macleod, Michael Mulkay, and Peter Weingart, eds., Perspectives on the Emergence of Scientific Disciplines (The Hague: Mouton, 1976); Russell H. McCormmach, "Editor's Foreword,' Historical Studies in the Physical Sciences, 1971, 3:ix-xxiv; Kohler, From Medical Chemistry, Ch. I., "Introduction: On Discipline History," pp. 1-8; David Edge and Michael Mulkay, Astronomy Transformed: The Emergence of Radio Astronomy in Britain (New York: Wiley, 1976); Rosenberg, "On The Study of American Biology and Medicine"'; Darryl Chubin, "State of the Field: The Conceptualization of Scientific Specialties," Sociological Quarterly, 1976, 17:448-476; Ronald C. Tobey, Saving the Prairies: The Life Cycle of the Founding School of American Plant Ecology, 1895-1955 (Berkeley/Los Angeles: Univ. California Press, 1981).

${ }^{15}$ For a recent discussion, see Thomas L. Hankins, "In Defence of Biography: The Use of Biography in the History of Science," Hist. Sci., 1979, 17:1-16.
} 
To pose such alternatives is to underline their arbitrariness. Every man or woman of intellect is both a more or less competent and original practitioner of his or her discipline and at the same time a navigator among a generation specific structure of options. ${ }^{16}$ The same considerations apply, of course, to any group small enough to share a problem-defined identity.

I do not mean to suggest that study of the scientist's life course is easily accomplished or, more significantly, that when accomplished it provides a simple and well-marked road to historical understanding. This approach does not guarantee answers, but it does provide an inclusive way of framing questions and ordering data; it is an approach that necessarily includes social, institutional, and intellectual factors in a structured context. A life as lived is a particularly valuable sampling device for the historian; for life is not a seamless web of experience, but can be examined at significant points in time, moments which inevitably present particular configurations of social possibility. In Wilhelmian Germany, for example, an individual's class and religion (as well as other factors) played a role from birth on in determining the likelihood of that individual's embarking upon an academic career. Entrance into secondary school constituted another point at which decisions were made and a new set of prospective likelihoods defined. The choices for a student in a classical Gymnasium were obviously different from those available to his age-mate in a Realschule. Later in a scientist's life, more specifically academic choices had to be made-of discipline, of thesis adviser, of dissertation subject, of first employment. And each choice can be seen as having been made among a particular configuration of options-while determining to some extent an individual's future choices.

It is true that history may legitimately ask its practitioners to transcend the time-bound perceptions of those past actors who constitute its scholarly subject matter; basic social patterns may well elude the understanding of even the most perceptive living through them and fundamental social change may at times be imperceptible to those experiencing it. On the other hand, it is the historian's unavoidable task to understand time- and culture-bound perceptions and assumptions, and at the same time to place his actor's perception in more general-exterior-terms. Historians have to perform two different tasks: to see the past in the same terms as those who lived in it, yet at the same time stand apart from those perceptions and evaluate their implications for the functioning of a social system or the initiation of change in that system. In this collective enterprise, the ability to follow individuals and small groups through their life course is an indispensable tool. Historians of science should-and I hope willundertake such studies in ever-increasing numbers.

I have already suggested a second trend that will certainly continue to thrive in the near future, and that is the still-burgeoning interest in the ideological uses of science. It is unlikely that this problem will be ignored; it is too central to our culture. It is equally obvious that we will continue to have a steady growth

${ }^{16}$ J. D. Watson, The Double Helix: A Personal Account of the Discovery of the Structure of DNA (New York: Atheneum, 1968). For an ingenious use of the biographical form as an expository device, treating a particular disciplinary group, see Russell McCormmach, Night Thoughts of a Classical Physicist (Cambridge/London: Harvard Univ. Press, 1982). I have discussed the historical uses of an approach emphasizing the structure of social options in "History and Experience," in The Family in History, ed. Charles Rosenberg (Philadelphia: Univ. Pennsylvania Press, 1975), pp. 1-11. 
of work in twentieth-century science, especially its support structures and relationships to the applied sectors. Academics live in a world of government subventions, of foundations, of problematic relationships with industry; as these realities force themselves upon even the most cloistered consciousness we can hardly expect our students to ignore them. The interest in the place of science in American society can only increase with the everyday impact of that science. Our generation's crisis in work and technology, in environmental pollution and energy resources, our struggles over military procurement, our attempts to cope with the information revolution have become staples of social and political debate at almost every level of society. They will soon become staples in our doctoral seminars and then in the pages of dissertation abstracts and our scholarly journals.

The last few decades have underlined ways in which science has functioned as ideology; but we must live with the fact that it is more than that. Science and technology have produced both the hard tomatoes we encounter every day in our supermarkets and the hydrogen bombs that recur in our nightmares. The ideas and authority of science and technology are not mere mystification; they have created the possibility of new social choices even if they do not determine how these choices are to be exercised.

I have been asked occasionally why we need a peculiar field of the history of science; and the discipline, if such it is, does threaten on occasion to polarize terminally and recrystallize into a social history, on the one hand, indistinguishable from social history generally and, on the other, into an intellectual history reflecting the several competences of contemporary scientists. But this would hardly be a desirable state of things. The peculiarly hybrid and increasingly eclectic character of the history of science is its most convincing reason for being. Without a specialized understanding of scientific ideas, historians can understand neither the social choices created by science nor the community within which these new ideas are elaborated. Obviously, as well, there is a place for largely or even exclusively internalist studies; for they reflect significant intellectual questions and emotional commitments. Similarly, there will always be an important place for the increasingly sophisticated study of the social forms and social impact of science and technology. But it is the peculiar task of the discipline of the history of science as a collective enterprise to constitute, represent, and synthesize all these points of view-perhaps not so much in the work of particular individuals, as in the aggregate of many such individual efforts.

In some ways, as I have argued, the disjunction between internal and external remains the historian of science's central continuing dilemma; for it transcends intradisciplinary problems of status and intellectual conflict and represents in microcosm more general social disjunctions which have become oppressively apparent in the past generation. The social understanding of science is too important to be left to the scientists; and we cannot have a history of science without that science. The categorical distinction between ideas and behavior may be useful in some areas of historical analysis, but it makes precious little sense in an arena where ideas and writings are fundamental behaviors. The acts of the mind are still acts, and in this case acts with consequences vast and still undetermined. 